\title{
Perchance to Dream
}

DOI:

10.1017/S0963180117000627

\section{Document Version}

Accepted author manuscript

Link to publication record in Manchester Research Explorer

\section{Citation for published version (APA):}

Brassington, I. (2018). Perchance to Dream: Pathology, Pharmacology, and Politics in a 24-Hour Economy.

Cambridge Quarterly of Healthcare Ethics, 27(2), 295-305. https://doi.org/10.1017/S0963180117000627

\section{Published in:}

Cambridge Quarterly of Healthcare Ethics

\section{Citing this paper}

Please note that where the full-text provided on Manchester Research Explorer is the Author Accepted Manuscript or Proof version this may differ from the final Published version. If citing, it is advised that you check and use the publisher's definitive version.

\section{General rights}

Copyright and moral rights for the publications made accessible in the Research Explorer are retained by the authors and/or other copyright owners and it is a condition of accessing publications that users recognise and abide by the legal requirements associated with these rights.

\section{Takedown policy}

If you believe that this document breaches copyright please refer to the University of Manchester's Takedown Procedures [http://man.ac.uk/04Y6Bo] or contact uml.scholarlycommunications@manchester.ac.uk providing relevant details, so we can investigate your claim.

\section{OPEN ACCESS}


Perchance to Dream: Pathology, Pharmacology and Politics in a 24-hour Economy

\author{
Iain Brassington
}

\begin{abstract}
The lack of sleep is a significant problem in the modern world. The structure of the economy means that 24-hour working is required from some of us, sometimes because we are expected to be able to respond to share-price fluctuations on the other side of the planet, sometimes because we are expected to serve kebabs to people leaving nightclubs, and sometimes because lives depend on it. The immediate effect is that we feel groggy; but there may be much more sinister long-term effects of persistent sleep deprivation and disruption, the evidence for which is significant, and worth taking seriously. If sleeplessness has a serious impact on health, it represents a notable public health problem. In this paper, the author sketches that problem, and looks at how exploiting the pharmacopoeia (or a possible future pharmacopoeia) might allow us to tackle it. He also suggests that using drugs to mitigate or militate against sleeplessness is potentially morally and politically fraught, with implications for social justice. Hence whatever reasons we have to use drugs to deal with the problems of sleeplessness, we ought to be careful.
\end{abstract}

Key words: sleep deprivation, pharmacopoeia, sleeplessness, drugs to mitigate sleeplessness

Presumably, the point of biomedical innovations is to help make the world a better place. "Better" may be understood in utilitarian terms, in that at least some people live healthily for longer; or it may be understood "ideally", in that the world is made more just, irrespective of the consequences for net or average welfare. ${ }^{1}$ In many cases, utilitarian and ideal improvements will come together. But they might not, and some innovations may end up making the world less just, even as they increase aggregate welfare. In this paper, I shall seek to demonstrate how a possible addition to the pharmacopoeia that looks desirable on utilitarian grounds may raise worries about justice. 


\section{An End to Tiredness?}

It would be good for there to be less tiredness. Fatigue is detrimental to welfare in its own right: it makes us feel miserable. But it also makes people less productive, and it might make them more dangerous. For example, a tired driver is more likely to make errors of judgement and to have slower reaction times. The Royal Society for the Prevention of Accidents (RoSPA) asserts that

driver fatigue may be a contributory factor in up to $20 \%$ of road accidents, and up to one quarter of fatal and serious accidents. These types of crashes are about $50 \%$ more likely to result in death or serious injury as they tend to be high speed impacts because a driver who has fallen asleep cannot brake or swerve to avoid or reduce the impact. $^{2}$

Figures released by the British Government indicate that fatigue was a contributory factor in 1784 road accidents in 2015, 58 of them fatal and 1726 causing serious or slight injury. ${ }^{3}$ It is not hard to see why fatigue should be a concern.

What goes for driving goes for other activities. Thus a similar worry applies to medical personnel: mistakes in surgery or dosage are more likely when the healthcare professional is tired. ${ }^{4}$ These mistakes may be trivial, but they could easily be lifealtering or life-ending. Adi Aran et al have presented evidence that a period of longer than 24 hours without sleep corresponds to lower attention, and that that correlates to riskier decisions being made. ${ }^{5}$ Drawing on work published by Christopher Landrigan et $a l^{6}$, Lisa Wolf et al state that

[t]here is compelling evidence to suggest that fatigue reduction interventions could contribute to overall improvements in the delivery of care, including reduction in medical errors ${ }^{7}$

- which is as much as to say that fatigue undermines quality of care. 
Yet there is room to be optimistic when it comes to confronting this phenomenon. Tiredness is a characteristic of the human body, and humans are basically talking biochemistry. If we can work out the biochemical characteristics of fatigue, it should be possible to come up with drugs to counter them. We do this in a hit-and-miss way already: strong coffee can help us feel more awake. But the wakefulness that caffeine provides might sometimes only give the illusion of alertness, thereby making us less aware that we're performing sloppily; and it might stop us sleeping when we get the chance, thereby making us even more tired later on. Were we to work out what is going on in the brain when we are fatigued, we could use that insight to develop more effective drugs to combat fatigue. On this basis, it would seem that we have prima facie good moral reasons to support this kind of research, and to make full use of whatever drugs it yields to eliminate tiredness.

A version of the "pharmaco-optimist" line of argument was mooted by An Ravelingien and Anders Sandberg in a 2008 paper that considers the possibility of minimising our need for sleep. Noting that "[o]ur society is becoming one of around the clock services and needs and it increasingly demands that we adapt our circadian rhythms to altered production schedules" ${ }^{8}$, they suggest that

a (technologically) optimistic scenario is that we may one day be able to diminish our need for shuteye to a few hours a night, or to delay it for several days, while the lengthened vigilance is still equivalent to the effect of normal sleep. ${ }^{9}$

They continue:

The drive for wake enhancement is in line with fundamental social values. By advancing our wakefulness, we promote our capabilities for autonomy, selfimprovement and actively taking part of and contributing to the world. By contrast, it may be argued that sleep - during which one is completely unconnected to reality, self and others - has no virtue aside of rather self-centred values of idleness. ${ }^{10}$ 
This obviously "pro-" argument is heightened by the language chosen: the phrase "wake enhancement" implies that wakefulness is a good thing, its increase better, and its absence bad. To call something an enhancement is already to imply that it is desirable. ${ }^{11}$

The benefits of wake-enhancement are clear. For instance, some medical emergencies crop up at 3am; we would seem to have a good moral reason to ensure that staff are as alert and clear-headed as possible. If drugs can help ensure that, we have a corresponding moral reason to ensure that those drugs are available. (We may even have a reason to require that medical staff would use them: I shall return to this expectation in a moment.) Much the same might well apply to a number of other walks of life: there is likely to be a need for taxi-drivers, air-traffic controllers, and so on, at all hours as well. In all these cases, "wake enhancement" may seem welfareoptimising; and since wake enhancement is not currently available, it adds weight to the idea that research into it would also be a good idea in order to maximise the chance that it will be available as soon as possible.

Admittedly, Ravelingien and Sandberg do note some lines of objection to their argument. In particular, they raise the possibility that there could be an expectation that workers would use wakefulness enhancers, asking whether we would be able to resist their lure granted that we live in a culture in which there are certain norms of productivity and success that would seem to make the drugs attractive. ${ }^{12}$ Still, they are sanguine in the face of such concerns. For them, the possibility that a technique such as wake enhancement may allow exploitation has to be considered in light of another possibility: that it will allow a kind of liberation, allowing us to create and take 
opportunities that we may otherwise have missed. Indeed, they suggest, such interventions may serve justice: granted that Smith may be better able to cope with less sleep as a matter of brute physiological luck, a drug might allow Jones to compete with him more effectively. ${ }^{13}$ This would level a playing field that had hitherto favoured Smith. Overall, they remain optimistic about the possibilities of using drugs and other interventions to help minimise or eliminate the problems presented by sleeplessness.

\section{Waking Nightmares}

It is possible, however, that Ravelingien and Sandberg are not quite as alert to the pitfalls of wake enhancement as they might be. In some areas of employment, there is a positive danger to third parties the likelihood of which is increased by tiredness. But tiredness also reduces productivity, and this is something that would concern any employer. It follows that in any occupation, employers would have a reason to prefer that employees take the drugs. Though Ravelingien and Sandberg articulate a concern about whether "[we will] have the freedom to withhold using wake enhancers, or [whether] the norms of success and maximum productivity [will] be too powerful", and about the "lure" of such drugs ${ }^{14}$, they do not analyse these possibilities: the first is framed as a rhetorical question that is not answered, and the second is simply met with a counter-assertion that there may be benefits to be had as well as risks. Yet the concerns linger; and the reasons employers (or employees) may have to prefer that wake enhancers be available could very easily give rise to an expectation that they be used. 
"Expectation" has two senses. It may be meant descriptively ("It would be no surprise to discover that wake-enhancement is used") or normatively ("One ought to use wakeenhancers"). The latter concerns me here.

It is conceivable that using the drugs could become a condition of employment. Such conditions may be implicit: an interviewee who was reassured that drugs to counter the effects of sleeplessness are available would be receiving a signal about the kinds of expectations that she would have to satisfy to get, or retain, the job. This is subtly, but clearly, coercive - she would be under economic pressure to do something that she might otherwise not do - and given some common-or-garden intuitions about autonomy, it may generate moral worries.

Naturally, not all workplace expectations are coercive, and not all coercion is indefensible. An employer who insists that naturist employees wear clothes to work on pain of dismissal is, in a way, putting those employees under pressure to do what they otherwise would not, to wit: dress. I take it that such pressure is not morally problematic (even granted that naturism is not immoral either). Neither does it matter too much what motivates the imposition of this fairly minimal dress-code, be it commercial, moralistic, or aesthetic. And so, granted that employers' coercive expectations that employees modify their behaviour in certain ways do not necessarily wrong those employees, may an expectation to use wake enhancers be defensible? May it not simply be up to employees to decide whether to take the drug? Perhaps not. 
To see why, it is worth looking at the answer to a boilerplate libertarian argument against smoke-free workplaces being enforced by law. In that case, the claim is that, so long as people know that they are likely to be exposed to second-hand cigarette smoke in the course of their employment behind a bar (for example), then it is up to them to decide whether to take the job or not. The analogy with taking wake enhancers should be clear: as long as they know what's expected of them in the course of a job, workers can make up their own minds, and decide to go elsewhere. However, the counterclaim is that potential bar staff simply do not have the luxury of choice: there may not be jobs available in smoke-free environments nearby (especially given that bar-owners have an incentive to provide a space for smokers, which makes it likely that the next bar down the street would also permit smoking, and that it would be hard to guarantee that staff would never have to work in there). As Richard Ashcroft puts it:

Labour markets being what they are, workforce members are relatively weak in bargaining over their conditions of employment, especially where they are in a service industry where consumer preferences are thought to be crucial. Unlike most consumers in bars, bar workers will be exposed to smoke all day, every day, without much say in the matter, and without control over how much they 'smoke'. It could be suggested that they could change employment, but many bar workers take this sort of work in circumstances where suitable alternative work is hard to find. Under these circumstances, one could argue that exposure to second-hand smoke is not free, and thus not consented to. ${ }^{15}$

Much the same kind of point could be raised in the present context. Labour markets being what they are, it may well be the case that suitable alternative work is hard to find; in that kind of case, the "decision" to use drugs to maintain wakefulness may be a decision in name only. 
This thought raises social justice concerns, because there is a class element to it. Jobs involving shift work and night work - that is, those that will disrupt regular sleep the most - are generally undesirable. This means that those with the most transferable skills would gravitate away from low-prestige jobs requiring night-work. In addition, the more senior one gets in an organisation, the lower the chance that one would have to work unsociable hours: in most cases, senior employees are more able to delegate night-work to those below them in the hierarchy. There will be walks of life, such as medicine, in which this pattern is defied to some extent; but the general rule holds. Since seniority correlates to class - because to be senior is to have attained a certain social position, and because people from middle-class backgrounds are more likely to have the educational opportunities that are necessary to obtain a senior position in the first place - we can predict from this that night-workers would disproportionately be from a lower social class.

If this is correct, the problem with people being expected to take drugs for reasons of employment is compounded by the plausible hypothesis that this expectation would weigh the most heavily on those who are already among the most economically underprivileged - and those both least likely to have the transferable skills to take their labour elsewhere and most likely to be vulnerable to their jobs being taken by others; and in a conventional economy, the benefits would accrue primarily to shareholders and the owners of capital. Hence whatever the utilitarian arguments for wake-enhancers, there would also seem to be an ideal aspect, to do with social justice and the distribution of the benefits and burdens of the enhancers, that ought to be addressed. 
It's worth noting that, even though there are utilitarian arguments for wake enhancement, there are also utilitarian reasons against. Irregular shift patterns also have unwelcome social consequences. Most lives are patterned around a conventional office-hours work model, with time in the evening for leisure. The free availability of drugs to counter the effects of sleeplessness may make it harder to resist taking on unusual work patterns, with the concomitant impact on social functioning.

We might also note that wake-enhancers' use invites the articulation of a worry about flourishing in the wide sense: an expectation that employees take drugs for the sake of the job reduces employees' moral status, in essence reducing them to component parts of the production process. It is arguable that this is what modern capitalist production does anyway - but that is no reason to extend the process. Bluntly, even if a drug would make it easier to behave like the Duracell Bunny, we would have a reason based in teleology, or the second formulation of the Categorical Imperative, or some fairly straightforward account of preference-satisfaction - to resist innovations that increase the chance of being treated as such. Indeed, even a utilitarian ought to be able to treat "flourishing" as a desirable end: the utilitarian arguments don't all head one way. That these worries can be cast equally well in broadly eudaimonistic, deontological, or utilitarian terms speaks for their salience.

Could we reconcile ourselves to a fully fledged 24-hour economy? If sleep patterns were to become matters of choice, the social norms about who does what and when would be disrupted; but this may not be a bad thing. Why not arrange dinner-dates for 4am if that's most convenient for you or your crush? If everyone has a pharmacologically-fluid body-clock, then might we not simply embrace this? 
We should not get carried away. There is a degree of circularity to endorsing the use of drugs to override our body clocks in order better to be able to accommodate the lifestyle made possible by those very drugs. Further, there would be consequences even for those working "normal" hours in a truly 24-hour world. Making work and socialising possible at any time means that there will always be things going on - and this means the noise and bustle of a normal working day would be inescapable, creating significant unwelcome knock-on effects for third parties. There would also quite possibly be undesirable consequences for nonhuman species living in cities.

Thus there is a number of concerns about a society in which wake-enhancers were freely available. Those concerns ought to inform debate about whether it is desirable to develop them. If we are concerned that the society that would be enabled is a society that on balance we would not want, then we have less of a reason to research wake enhancement; and if we decide that the availability of drugs would be positively undesirable, we have a reason not to.

The proviso is that, where there is a matter of public safety involved, wake enhancers may still be a good idea. Whatever the reasons we have to be suspicious of wakeenhancement, we have other reasons to use it when we are talking about its use by, inter alia, medics. Precisely because medical emergencies do not only happen during office hours, it is implicit in becoming a medic that one has accepted antisocial shifts as part of the job; this does not apply nearly so much in many other occupations. The justice concerns are also likely to be diluted: to be a medical professional is to hold a high-prestige position; more, it is to do a job that comparatively few others could do, 
which decreases vulnerability to coercion. This is not to say that medics never have workplace vulnerabilities - but the demand for them is not nearly so easily met as the demand for panel-beaters and data-entry clerks, so they do have a degree of leverage that others lack. (This point obviously does not apply to all those who may work shifts - driving taxis is not a prestige job - but even there, the public safety dimension may come up trumps.)

Finally, whatever pressure there is from employers in "vocational" sectors such as healthcare is unlikely to be morally quite the same as pressure from private-sector employers. Drugs would not be required for the sake of profitability, but for the sake of (a different kind of) public interest. Whatever the moral reasons against requiring a person to take a drug might be normally, there is a plausible-enough countervailing moral reason in this case to require it in certain exceptional cases pro bono publico.

\section{Sinister Sleeplessness}

Yet this is not the end of the questions raised by sleeplessness and pharmacological responses to sleeplessness; there are consequences considerably more serious than tiredness that arise from consistent sleep disruption and disturbance.

For example, a study of police officers - who, by the nature of the job, may have to work irregular hours - by John Violanti et al found that those whose work patterns combined night shifts with either less sleep or increased overtime could be at increased risk of metabolic syndrome (which they defined as "elevated waist circumference and triglycerides, low HDL cholesterol, hypertension, and glucose intolerance" 16 , but which can also be taken to cover a combination of diabetes, high 
blood-pressure, and obesity). As a possible explanation, the researchers offered the hypothesis that

midnight-shift officers were most likely to be sleep deprived because of difficulties associated with day sleeping, and sleep debt has been shown to have a harmful impact on carbohydrate metabolism and endocrine function that could contribute to metabolic disorders. ${ }^{17}$

In short, sleep disruption and deprivation can be associated with elevated risks of chronic ill-health. Clearly this makes persistent disruption and deprivation of sleep a bigger problem than simply causing tiredness.

A meta-analysis published in the British Medical Journal in 2012 appears to lend weight to worries about ongoing health problems related to shift-work and (by implication) circadian disruption more generally, having identified "an epidemiological association between shift work and vascular events", and noting results from other studies suggesting that "shift workers have higher rates of dyslipidaemia, metabolic syndrome, hypertension, and diabetes”. The authors add that [s]hift work is disruptive to circadian rhythm, impairs sleep quality, and affects worklife balance; and insomnia, a complaint common among night shift workers, is an independent risk factor for myocardial infarction. ${ }^{18}$

Correlation does not equate to causation (as the authors admit); but a clear and consistent correlation is significant evidence, and it would be foolhardy to dismiss it out of hand.

Metabolic illness and hypertension are arguably not the most serious outcomes of sleep disruption: a World Health Organization (WHO) study published in 2010 concluded that "shiftwork that involves circadian disruption is probably carcinogenic to humans"19. Breast cancer rates appear to be elevated in female flight crew and 
prostate cancer may be more frequent in male flight crew. It is possible that this has something to do with a misalignment of sleep patterns with natural day/ night patterns. ${ }^{20}$ The study also points out that

[c]hanges in the immune system have been shown to occur in partial (early or late night) sleep deprivation and comprise changes in the cytokine pattern that favours the Th2 group of cytokines and decreases Th1 cytokines (e.g. interferon $\gamma$ ) which act in cellular immune defence and in immune surveillance to counteract tumour growth. In the majority of studies of sleep deprivation, suppression of natural-killer-cell activity has been shown, and this also leads to a decrease in anti-tumour surveillance. ${ }^{21}$

Thus there is reason to think that consistently disrupted sleep patterns, and sleep patterns that misalign circadian and natural day/ night rhythms, have a significant impact on wellbeing not limited to transient feelings of fatigue: there is evidence that they might be life-shortening, all else being equal. ${ }^{22}$

If the links between sleep disruption and deprivation and illness are plausible, there would be a serious public health problem that arises from the way that we sleep or do not sleep. It would not be wildly hyperbolic to say that aspects of the modern economy are harmful to human health.

Ordinarily, identifying something as a threat to human health generates a moral reason to change the way that thing is used, with that change enforced by law if necessary. For example, if an industrial process causes health problems in workers, the factory owner has a moral reason, quite possibly amounting to a moral duty, to alter that process, or to provide extra safety equipment to the workforce. It is blameable either to refuse to act in a way that avoids an avoidable danger to others, or not to be diligent in respect of identifying potential threats. At the outside, we might think that a factory-owner whose processes cannot be performed safely ought to find 
something else to do. Correlatively, we might think that the government should take steps either to require alterations in dangerous industrial processes, to incentivise the adoption of alternative processes; and perhaps there are some processes that governments ought to ban altogether because they present an unacceptable risk to the people who work with those processes, and because governments have a role in minimising that risk.

If that kind of reasoning is persuasive, it would seem to apply pari passu to the case of illnesses caused by a lack of sleep and/ or disturbed sleep patterns. If there is plausible evidence that 24-hour working patterns are detrimental to health, then employers have a moral reason to do what they can to minimise or eliminate that risk for the sake of minimising avoidable and serious risks to employees - perhaps including not requiring such work at all.

Naturally, as with the more straightforward case of tiredness, the fact that there are risks with a behavioural pattern is not the whole story. An elevated risk of undesirable consequences is nothing more than a risk; and there are also reasons to make use of 24-hour work patterns. That there is a moral or public policy reason to do one thing (such as reducing night-time working) will not automatically trump the reasons that might obtain to do its opposite - and some of those latter reasons might themselves be perfectly defensible on moral or public policy grounds. For example, an economy such as the UK's benefits a great deal from things like banking and financial services; because the world does not keep the same hours, it may be desirable for there to be at least some activity in that sector at night. Even if we are in the end unmoved by this appeal, it is not incoherent. Similarly, infrastructure repairs cause less disruption if 
carried out when the majority of the working population is asleep. It is for this reason that sleep disruption and deprivation can be seen as generating a moral problem: there is (at least sometimes) a reason to make use of night-time work patterns, and a healthbased reason not to. Can the tension between the competing reasons be resolved?

\section{Time for Drugs}

One possible response to this problem is to make the case for the use of pharmacological interventions to minimise the risks from night-working: call this "circadian enhancement". As with wake enhancement, whatever the undesirable sequelae of sleep deprivation and disruption, there is no need for us to be beholden to them. While the relationship between body clock and illness may be complicated, there is nothing occult about it. Research could tell us more about exactly how the body clock works and what the consequences of upsetting it are on a molecular level; that ought to give us an insight into ways of reducing or even preventing the harm, either by finding ways to make the circadian rhythm more mutable, or by finding ways to reduce the knock-on effects of its immutability.

Indeed, it may be that there is some kind of moral imperative to carry out such research. This part of the argument builds on the claim, advanced above, that there is a perfectly defensible moral reason based on an appeal to public safety to ensure that at least some workers have access to wake-enhancers. The problem is that there is no reason to suppose that drugs to improve wakefulness would do anything to mitigate the more serious effects of circadian disruption. Indeed, wake enhancement may exacerbate these effects by making disrupted sleep patterns less of an immediate burden. This could lead to their being more widely accepted, or to greater degrees of 
disruption. Drugs that make it possible for people to work at night might be indirectly contributing to severe health problems. Again, the burden would likely fall disproportionately on more vulnerable workers.

If there are people whom we would want to work irregular hours, we should not be burdening them with health risks. As a matter of justice, it appears perfectly reasonable to say that the demos should not expect people to face an elevated risk to their health when that elevation arises in the service of the demos. (Increased wages to compensate for the additional risk would not resolve matters; it is better not to face the risk of cancer than to have to be paid more because one faces it.) Circadian enhancers, were they to be developed, might be a good option.

Worries about coercion may yet linger in this possible world. Employers and insurers would still have a reason to ensure reductions in risk from sleep deprivation to minimise liability. This may lead them to pressure workers to take circadian enhancers, even if they would not otherwise. However, such defensiveness from employers may not be warranted. In the wake enhancement scenario, the pressure arose from one's prospects of getting the job in the first place; now, there would be no particular reason for employers to pressure employees to take the drugs. Provided that the drugs (together with information about their uses, benefits, and drawbacks) were available, and assuming rational agency in the workers, something like the Millian "rickety bridge" principle would be more likely to apply; ${ }^{23}$ it could be left to competent adults to take or ignore whatever risk-mitigation measures they see fit, rather as they may choose healthy or unhealthy food in the canteen. 
Perhaps more importantly, there is (as I have already indicated) a moral reason in relation to things like medicine to work strange hours and to take wake enhancers that simply does not exist in respect of the private sector: it is intuitively appealing to say that working to save lives is morally very different from the pursuit of shareholder profit, and that 24-hour availability for medical services is a part of what a decent society would seek to provide in a way that 24-hour pursuit of profit isn't. (This does not mean that profit is a bad thing: simply that it is not of overriding concern.) Therefore worries about wake-enhancement for medical staff, the damaging effects of which are appropriately softened by circadian enhancement, may be warranted in a way that is not the case in respect of the pursuit of private sector profitability.

\section{Should we Lose Sleep about Losing Sleep?}

Questions about sleep, and its absence, engage a range of bioethical and nonbioethical subdisciplines. Inasmuch as that they are related to something that may well have an impact on all of us, they belong to public health ethics. But they also belong to economics, and to policy, and to science and technology ethics. Within the space of one paper, it is not possible to do justice to all of the potential debates. Exactly where we locate ourselves in these debates, and where we think we should locate ourselves, will depend on our particular theoretical commitments; those arguments must be made in another paper.

Even so, there is a few claims we can make about avenues of enquiry that may be worth investigating. First, being tired is a bad thing - it is welfare-affecting, and may increase risks to third parties. This means that we have at least a reason to use "wake enhancers"; and this reason generates a further reason to carry out research on such 
drugs. For some people, the reason to use wake enhancers may have at least some of the characteristics of a moral imperative; and though a moral reason to use them cannot generate a moral reason to invent them, it would not take too much effort to argue that the imperative underpinning their use also - and in parallel - generates an imperative for research. ${ }^{24}$ There is at least a corresponding moral reason to engage in research that might provide, and to make available, what I have called "circadian enhancers": drugs that could prevent or reverse the risks and harms that appear to derive from disruption of normal waking hours and that may be exacerbated by wake enhancement in the Ravelingien and Sandberg mould. If there are some people whom we have a reason to prefer to work at night, then it seems that we might have a reason also to protect them from the effects of that.

In all these cases, though, there is a threat that the availability of wake-enhancers and circadian enhancers may open the way for workplace exploitation, especially among already-vulnerable workers. Some workers might be expected to use wake enhancers; but we also have a range of moral reasons to guard against this expectation becoming normalised. Thus we should take care with any research into, or distribution of, drugs that assist with sleeplessness. They may make some people's lives worse. Who can tell what dreams may come?

\footnotetext{
1 I borrow these uses of the terms "utilitarian" and "ideal" from Ronald Dworkin. See Dworkin D. Positive Discrimination. In: Taking Rights Seriously. London: Bloomsbury; 2013:279. ${ }^{2}$ Royal Society for the Prevention of Accidents. Driver Fatigue and Road Accidents. Birmingham: RoSPA; 2011: http://www.rospa.com/rospaweb/docs/advice-services/roadsafety/drivers/driver-fatigue-2011.pdf (accessed August 6, 2017)

${ }^{3}$ Department for Transport. Reported Road Casualties Great Britain: 2015 Annual Report. London: Department for Transport; 2016:303.

${ }^{4}$ McCormick F, Kadzielski J, Landrigan C, Evans B, Herndon H, Rubash H. Surgeon Fatigue: A Prospective Analysis of the Incidence, Risk, and Intervals of Predicted Fatigue-Related Impairment in Residents. Archives of Surgery 2012;147(5):430-435; Garrouste-Orgeas M, Flaaten H, Moreno R. Understanding Medical Errors and Adverse Events in ICU Patients. Intensive Care Medicine 2016;41(1):107-109; Cf. West C, Tan A, Habermann T, Sloan J,
} 
Shanafelt T. Association of Resident Fatigue and Distress with Perceived Medical Errors. Journal of the American Medical Association 2009;302(12):1294-1300.

${ }^{5}$ Aran A, Wasserteil N, Gross I, Mendlovic J, Pollak Y. Medical Decisions of Pediatric Residents Turn Riskier after a 24-Hour Call with No Sleep. Medical Decision Making 2017;37(1):130-131.

${ }^{6}$ Landrigan C, Czeisler C, Barger L, Ayas N, Rothschild J, Lockley S. Effective Implementation of Work-Hour Limits and Systemic Improvements. The Joint Commission Journal on Quality and Patient Safety, 2007;33(11):19-29.

7 Wolf L, Perhats C, Delao A, Martinovich Z. The Effect of Reported Sleep, Perceived Fatigue, and Sleepiness on Cognitive Performance in a Sample of Emergency Nurses. Journal of Nursing Administration 2017;47(1):47.

${ }^{8}$ Ravelingien A, Sandberg A. Sleep Better than Medicine? Ethical Issues Related to 'Wake Enhancement'. Journal of Medical Ethics 2008;34(9):e9.

${ }^{9}$ See note 8, Ravelingien, Sandberg 2008.

${ }^{10}$ See note 8, Ravelingien, Sandberg 2008:e9; slightly modified.

${ }^{11} \mathrm{Cf}$ Harris J. Enhancing Evolution, Princeton: Princeton University Press; 2007:9

12 See note 8, Ravelingien, Sandberg 2008.

${ }^{13}$ See note 8, Ravelingien, Sandberg 2008.

${ }^{14}$ See note 8, Ravelingien, Sandberg 2008.

${ }^{15}$ Ashcroft R. Smoking, Health, and Ethics. In: Dawson A, ed. Public Health Ethics: Key Concepts and Issues in Policy and Practice. Cambridge: Cambridge University Press; 2011:94 (slightly modified).

${ }_{16}$ Violanti J, Burchfiel C, Hartley T, Mnatsakanova A, Fekedulegn D, Andrew M et al. Atypical Work Hours and Metabolic Syndrome Among Police Officers. Archives of Environmental \& Occupational Health 2009;64(3):194.

${ }_{17}$ See note 16. Violanti, Burchfiel, Hartley, Mnatsakanova, Fekedulegn, Andrew et al 2009:198.

${ }^{18}$ Vyas M, Garg A, lansavichus A, Costella J, Donner A, Laugsand L, et al. Shift Work and Vascular Events: Systematic Review and Meta-Analysis. British Medical Journal 2012;345: e4800 (slightly altered).

${ }^{19}$ World Health Organization International Agency for Research on Cancer. IARC

Monographs on the Evaluation of Carcinogenic Risks to Humans, vol. 98: Painting, Firefighting, and Shiftwork, Lyon: International Agency for Research on Cancer; 2010:764 (emphasis original).

20 See note 19, World Health Organization International Agency for Research on Cancer 2010:762.

${ }^{21}$ See note 19, World Health Organization International Agency for Research on Cancer 2010:762-3.

${ }^{22}$ See also Papagiannakopoulos T, Bauer M, Davidson S, Heimann M, Subbaraj L, Bhutkar A, et al. Circadian Rhythm Disruption Promotes Lung Tumorigenesis. Cell Metabolism 2016;24(2):324; but cf. Lucassen E, Coomans C, van Putten M, Kreij S, van Genugten J, Sutorius R et al. Environmental 24-hr Cycles Are Essential for Health. Current Biology 2016;26(14):R669. They suggest that the effects of circadian disruption may be reversible. ${ }^{23}$ The essence of the example is this: that (Mill claims) if you are about to cross a dangerous bridge knowing that it is dangerous but freely accepting that danger, I do not have the right to intervene to stop you - your own good is not sufficient warrant. See Mill JS On Liberty (London: Penguin; 1985): 166

${ }^{24}$ I have argued extensively elsewhere that there is not a duty to support scientific research: see Brassington I. John Harris' Argument for a Duty to Research. Bioethics 2007;21(3):160; Brassington I. Defending the Duty to Research? Bioethics 2011;23(1):21. A re-worked version of these papers appears as chapters 8 and 9 of Brassington I Bioscience and the Good Life (London: Bloomsbury; 2013). Whether my conclusion here forces a modification of my earlier position, or is unexpectedly compatible with it, or is the exception that proves the rule, I am not entirely sure. 